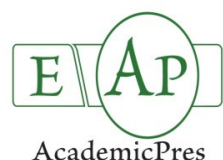

AcademicPres

\title{
Determination of Cyclotrichium niveum Essential Oil and Its Components at Different Altitudes
}

\author{
Memet INAN ${ }^{1 *}$, Ahmet Zafer TEL ${ }^{2}$ \\ ${ }^{1}$ Adiyaman University, Kahta Vocational School, Medicinal and Aromatic Plants, 02400, Adiyaman, Turkey; \\ minan@adiyaman.edu.tr(*correspondingauthor) \\ ${ }^{2}$ Adiyaman University, The Faculty of Science and Letters, Department of Biology, 02400 Adiyaman, Turkey; aztel@adiyaman.edu.tr
}

\begin{abstract}
Cyclotrichium niveum (Boiss.) Manden. \& Scheng. is a perennial species of Lamiaceae family of high importance due to essential oils compounds. Essential oil rates and essential oil components were determined in plants of this species collected from different altitudes. In order to have specific data, the plants were harvested from their natural growing area; the samples were picked up during full flowering period, from three different altitudes $(890 \mathrm{~m}, 1239 \mathrm{~m}$ and $1605 \mathrm{~m})$ in order to enhance that essential oil rates are directly influenced by this aspect. The analysis of essential oil extracted included 42 components and pulegone was the main component among these. Whereas the lowest pulegone rate was determined as $59.9 \%$ at $890 \mathrm{~m}$ altitude, the highest value (68.12\%) was determined at $1605 \mathrm{~m}$. It was also determined that as the altitude increased, the rate of this particular component in essential oil also increased, while the rate of other important components (such as isomenthone, limonene, 1,8-cineole, isopulegone) decreased.
\end{abstract}

Keywords: Cyclotrichium niveum, elevation, pulegone, secondary metabolites

\section{Introduction}

It is known that several internal and extrinsic factors are efficient on the secondary metabolites in medicinal and aromatic plants (Chalchat et al., 1997; Hudaip et al., 2002; Kofidis and Bosabilidis, 2008; Panou-Filotheou et al., 2001; Takaloo et al., 2012). Essential oils included among the secondary metabolites group produced by the plants have been intensely used in food industry due to their aromatic and protective properties (Smith-Palmer et al., 2001). Structures of the secretory hairs and the amount of secreted substances existing on the surface of leaves of plants growing at different altitudes can be different. It has been reported by some researchers that however the number of epidermal tissues on the surface of leaf and the density of hair on leaf surface, the amount of secreted essential oil increases with the altitude (Bosabalidis, 2002; Kofidis and Bosabilidis, 2008). Similarly, the rate of essential oil and essential oil components are affected by different altitudes. It has also been determined in several studies that have been carried out with different plants, that as the altitude increases, the rate of essential oil decreases (Delazar et al., 2011; Gulbaba et al., 2002; Haider et al., 2009), which is in agreement with our conclusions as well.

Cyclotrichium niveum (Bois.) Mandan. \& Scheng. a member of the family Lamiaceae is a perennial species endemic for Turkey, which have a significant release of essential oil (Başer et al., 1994; Dirmenci et al., 2010; Sanon et al. 2007; Tel, 2009). Essential oils are complex compounds and their chemical composition and concentration of elements show great changes. Essential oils, terpenoids, phenylpropanoids and benzenoids, existing in the plants as the secondary metabolites, can be present as fatty acid derivatives and amino acid derivatives (Lodhia $e t$ al., 2009).

In dried leaves of $C$. niveum, essential oil exists at a rate of 5.6\% (Baytop, 1984). Depending upon the picking period of the plant and the used sample organ, this amount of essential oil can vary between 1.5-2.1\% (Alim et al., 2009; Başer, 2002; Cetinus et al., 2007; Goze et al., 2010). The main components of this essential oil are pulegone and isomenthone (Başer, 2002). It has been determined that in the essential oil samples taken out from different organs of plants, the rate of pulegone varies between $32.5-56.4 \%$ and the rate of isomenthone varies between 34.2-35.4\% (Basser et al., 1994). It has been reported that $76.84 \%$ pulegone and $6.65 \%$ isomenthone exists in the essential oil extracted from the upper section of plants (Cetinus et al., 2007). Alim et al. (2009) reported that they determined 26 leading components in C. niveum essential oil from plants picked in full blossoming period; the rate of pulegone was determined as $50.46 \%$. the rate of isomenthone was determined as $34.53 \%$, while limonene (\% 2.11), 1,8-cineole (\% 1.91), Yelement (\% 1.53), gama-pentene (\% 1.46) were the subsequent.

Studies related to essential oil components existing in different organs of $C$. niveum species have been carried out and reported in speciality literature. This study aimed to determine the effect of different altitudes upon the rate of essential oil and essential oil components in $C$. niveum plants growing naturally. 
Materials and methods

\section{Plant Material}

C. niveum plants were collected from three different altitudes upon the road of Adiyaman/ Kahta/ Değirmenbaşı - Malatya (West of Mount Nemrut). The dates on which plants were picked up, the coordination and pick-up altitudes are presented in Tab. 1. The determinations of plants collected in full-flowering period was conducted by Ahmet Zafer Tel (Adiyaman University, Faculty of Arts and Science, Department of Biology) and their herbariums were recorded in the aforementioned faculty (Voucher No: Tel 8881). Because blossoming was earlier at lower altitudes, the dates for collection of the plants differ. Whereas flowering in low altitudes was at the beginning of July, it occurred towards the end of July as the altitude increased. After the plants were picked up, they were naturally dried in a shady, breezy area, and stalk-leaf separation was performed.

Tab. 1. Collecting dates, coordination and altitudes of sample picking locations for Cyclotrichium niveum (Bois.) Mandan \& Scheng plants

\begin{tabular}{cccc}
\hline Location & $\begin{array}{c}\text { Collected } \\
\text { Date }\end{array}$ & Coordination & $\begin{array}{c}\text { Altitude } \\
(\mathrm{m})\end{array}$ \\
\hline Location 1 $\left(\mathrm{L}_{1}\right)$ & 04.07 .2013 & $\begin{array}{c}37^{\circ} 57^{\prime} 44^{\prime \prime} \text { North } \\
38^{\circ} 40^{\prime} 20^{\prime \prime} \text { East }\end{array}$ & 890 \\
Location 2 $\left(\mathrm{L}_{2}\right)$ & 12.07 .2013 & $\begin{array}{c}38^{\circ} 01^{\prime} 08^{\prime \prime} \text { North } \\
38^{\circ} 43^{\prime} 51^{\prime \prime} \text { East }\end{array}$ & 1239 \\
\hline Location 3 $\left(\mathrm{L}_{3}\right)$ & 25.07 .2013 & $\begin{array}{c}38^{\circ} 00^{\prime} 30^{\prime \prime} \text { North } \\
38^{\circ} 45^{\prime} 36^{\prime \prime} \text { East }\end{array}$ & 1605 \\
\hline
\end{tabular}

\section{Essential Oil Analysis}

The leaves separated from stalks were boiled in Clevenger type steam distillation device for 3 hours, with 3 replications from the samples taken out of each location. The averages determined with 3 replications were found and compounded oils were put into bottles for GC/MS analysis and stored at $+4^{\circ} \mathrm{C}$ temperature.

\section{Gas Chromatography Mass Spectrometry (GC/MS) Analysis}

The analysis of essential oils of $C$. niveum was carried out by using Thermo Scientific Focus Gas Chromatograph equipped with MS, auto sampler and TR-5MS (0.25 mm x $60 \mathrm{~m}$ i.d, film thickness 0.25$)$. The carrier gas was helium (99.9\%) at a flow rate of $1 \mathrm{~mL} / \mathrm{min}$; ionization energy was $70 \mathrm{eV}$. Mass range $\mathrm{m} / \mathrm{z}$ 50-650 amu. Data acquisition was scan mode. MS transfer line temperature was $250{ }^{\circ} \mathrm{C}$, MS ionization source temperature was $220{ }^{\circ} \mathrm{C}$, the injection port temperature was $220^{\circ} \mathrm{C}$. The samples were injected with 250 split ratio. The injection volume was $1 \mu \mathrm{L}$. Oven temperature was programmed in the range of 50 to $220^{\circ} \mathrm{C}$ at $3{ }^{\circ} \mathrm{C} / \mathrm{min}$. The structure of each compound was identified by comparison with their mass spectrum (FFNSC13 and Wiley9 library). The data were handled using Xcalibur software program.

\section{Soil and Temperature}

Soil samples from the experimental locations contained low organic matter $(0.32 \%)$, salt content of $0.017 \%, \mathrm{pH}$ of $7.90 \%$ and the texture was clay (Celik, 2012). According to the long-term meteorological record, the average temperature values in July were $26.8^{\circ} \mathrm{C}$ in the research area.

\section{Results and discussion}

\section{Essential Oil}

The rate of essential oil can be affected by several factors. Some studies have revealed that the altitude negatively affects the rate of essential oil and yield (Delazar et al., 2011; Gulbaba et al., 2002; Haider et al., 2009). In this study that we carried out on $C$. niveum, we determined that as the altitude increased, the rate of essential oil obtained from plants decreased. In accordance to this, the rate of essential oil in plants picked up from $\mathrm{L}_{1}(890 \mathrm{~m}), \mathrm{L}_{2}(1239 \mathrm{~m})$ and $\mathrm{L}_{3}$ $(1605 \mathrm{~m})$ locations were $5.5 \%, 4.8 \%$ and $4.1 \%$, respectively (Tab. 2). These determined data were higher than the results reported by other researchers (Alim et al., 2009; Başer, 2002; Cetinus et al., 2007; Goze et al., 2010). This difference might probably be resulted from the section of plant, climate, geographical position, soil structure, etc.

\section{Chemical Composition of the Essential Oil}

The components of essential oil obtained from $C$. niveum plants are presented in Tab. 2, while the changes of significant components, at different altitudes of the 3 locations, are shown in Fig. 1.

As a result of $\mathrm{GC} / \mathrm{MS}$ analysis, specifically 42 compounds were determined as leading in $C$. niveum essential oil. Total rate of components in essential oil extracted from samples collected at the lowest altitude was $95.12 \%, 96.87 \%$ for the second location, and $96.13 \%$ for the highest altitude location. Pulegone, isomenthone, 1,8cineole and limonene components included almost $86 \%$ of the total essential oil structure. According to the average obtained for the three locations, pulegone was the main component, having almost $65 \%$ of the essential oil composition.

Puleone amount increased with the altitude. In accordince to this, whereas the lowest pulegone value was obtained from $\mathrm{L}_{1}$ point as $59.9 \%$, the rate of pulegone in plants picked up from $\mathrm{L}_{2}$ and $\mathrm{L}_{3}$ was $65.23 \%$ and $68.12 \%$, respectively. These values we determined for pulegone component are higher than the values of some researchers (Alim et al., 2009; Başer et al., 1994), Cetinus et al. (2007); they have reported lower values than ours (50.46\%). This situation can be caused by different locations and altitudes.

As the altitude increased, the rates of some components in essential oil, such as limonene, 1,8-cineole, isomenthone, isopulegone, exo-isocamphonone, were determined to decrease, in contrast to pulegone. A similar case was also observed for some other constituents, while components such as verbenone, citronellol, ocimenone, spathulenol, selinene, and naphthalenone were determined to increase in rate, once with the altitude. 
130

Tab. 2. Essential oil rates and components obtained from C. niveum plants collected from different altitudes (\%)

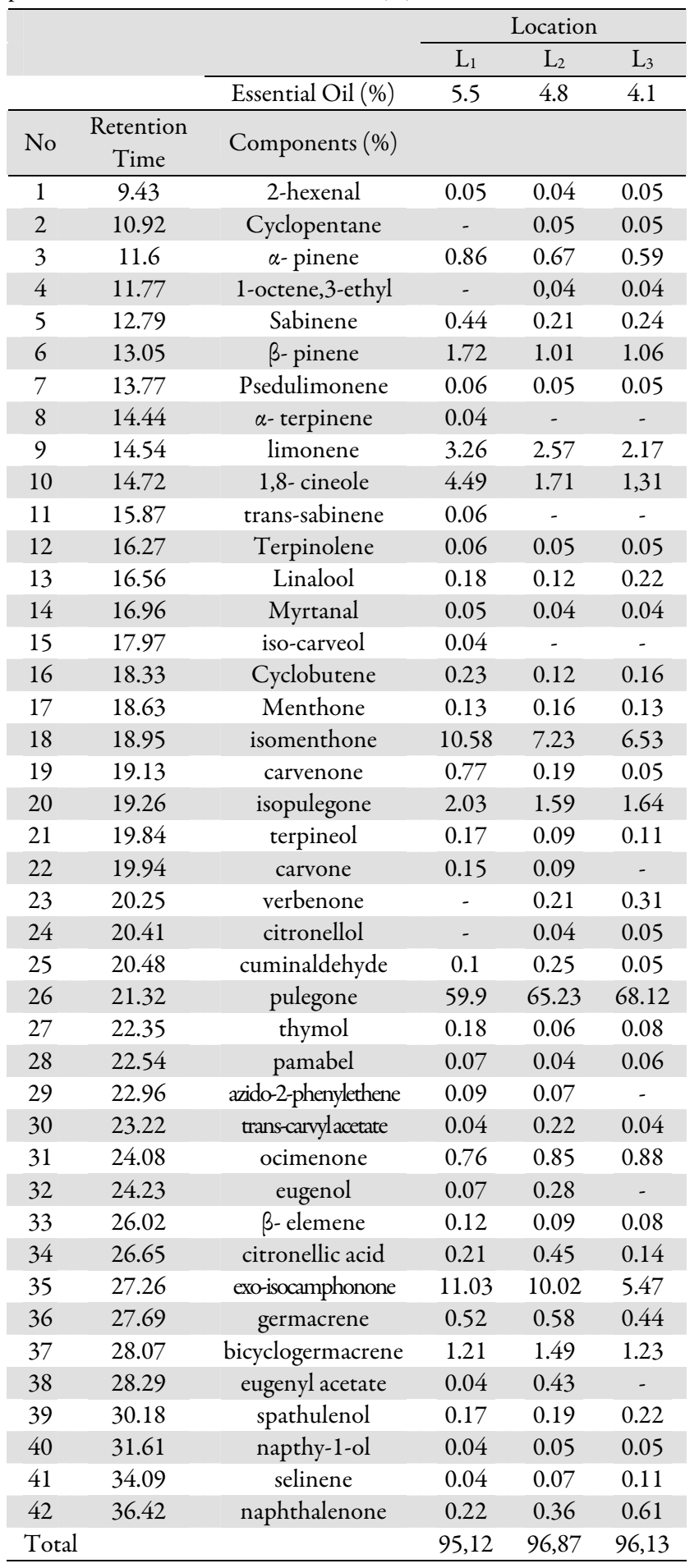

The results we determined related to isomenthone component, varying from 6.53 for $\mathrm{L}_{3}$ to 10.58 for $\mathrm{L}_{1}$, had lower values than the results reported in previous studies (Alim et al., 2009; Başer et al., 1994).

Some of the components could not be determined in essential oils of the plants collected from the lowest altitude (cyclopentane, verbenone, citronellol) nor at the highest altitude (components such as $\alpha$ - terpinene, trans-sabinene, iso-carveol, carvone) (Tab. 2).

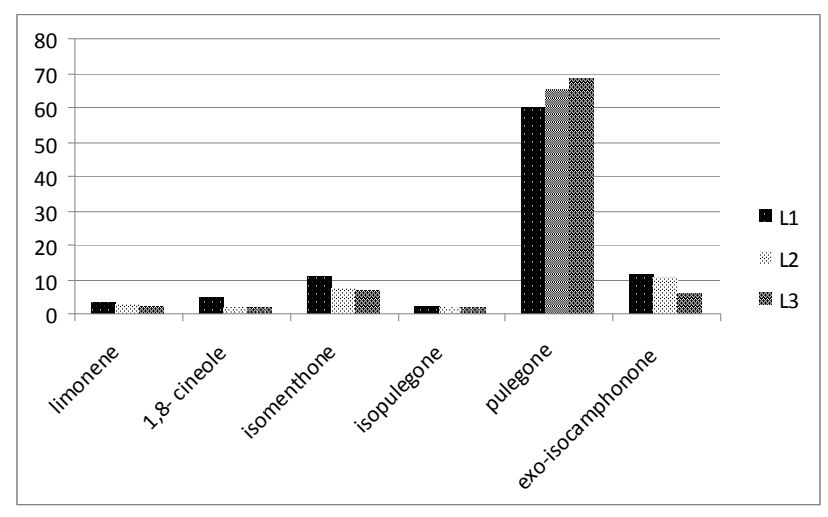

Fig 1. Changes of important components of C. niveum essential oil extracted from samples from different altitudes

On the other hand, several components, such as limonene, 1,8-cineole obtained from plants picked up from the lowest altitude $\left(\mathrm{L}_{1}\right)$ were determined to be higher in comparison with the data recorder for higher altitudes.

There has been no literature related data for exoisocamphonone component, in studies carried out on essential oil extracted from plants. Whereas in the current study, this component was determined with $11.03 \%$ at the lowest altitude, while its rate at the highest altitude decreased to $5.47 \%$.

These changes in essential oil composition are probably caused by photoperiod and air temperature at different altitudes.

\section{Conclusion}

All important components determined at high rate in $C$. niveum essential oil were negatively or positively affected by altitude. Even more, the data determined that as the altitude increased, the essential oil in $C$. niveum plants decreased proportionally. The highest rate of pulegone, as one of the most important components of the essential oil, was determined at high altitudes, but some other important components, such as isomenthone, 1,8-cineole, limonene, isopulegone decreased in rate as the altitude increased.

\section{Acknowledgement}

The authors would like to thank Prof. Dr. Elif Sultan Giray for her contribution to this work.

\section{References}

Alim A, Goze I, Cetin A, Atas AD, Vural N, Donmez E (2009). Antimicrobial Activity of the Essential Oil of Cyclotrichium niveum (Boiss.) Manden. Et Scheng. Afr J Microbiol Res $3(8): 422-425$.

Başer KHC, Sarikardasoglu S, Tümen G (1994). The Essential Oil of Cyclotrichium niveum (Boiss.) Manden. Et Scheng. J Essen Oil Res 6:9-12.

Başer KHC (2002). Aromatic biodiversity among the flowering plant taxa of Turkey. Pure Appl Chem 74(4):527-545.

Baytop T (1984). Therapy With Medicinal Plants in Turkey (Past and Present). Publication of Istanbul University, $480 \mathrm{p}$. 
Bosabalidis AM (2002). Structural features of Origanum sp. In S.E. Kintzios (ed.), Oregano. The Genera Origanum and Lippia. Taylor and Francis Press, London, 64 p.

Chalchat JC, Garry RP, Michet A (1997). Variation of the chemical composition of essential oil of Mentha piperita L. during the growing time. J Essent Oil Res 9:463-465.

Celik, A (2012). Determination of the potential raw materials of the non-arable areas of the Adiyaman povience for use in birck-ceramic production. Cukurova University, Institute of Natural and Applied Sciences, Adana, Turkey, phD Diss. Abstr.128-147.

Cetinus ŞA, Goze İ, Saraç B, Vural N (2007). Scavenging Effect and Antispasmodic Activity of The Essential Oil of Cyclotrichium niveum. Fitoterapia 78:129-133.

Delazar A, Bahmani M, Shoar HH, Raisi AT, Asnaashari S, Nahar L, Sarker SD (2011). Effect of Altitude, Temperature and Soil on Essential Oil Production in Thymus fedtschenkoi Flowers in Osko and Surrounding areas in Iran. J Essen Oil Bearing Plants 14(1):23-29.

Dirmenci T, Dündar E, Deniz G, Arabacı T, Martin E, Jamzad Z (2010). Morphological, karyological and phylogenetic evaluation of Cyclotrichium: a piece in the tribe Mentheae puzzle. Turk J Bot 34:159-170.

Goze I, Cetin A, Goze A, (2010). Investigation of Effects of Essential Oils of Origanum minutiflorum O. Schwarz $\mathrm{PH}$ Davis and Cyclotrichium niveum (Labiatae) Plants on Angiogenesis in Shell-Less chick Embryo Culture. African J Biotech 9(14):2156-2160.

Gulbaba GA, Özkurt N, Kurkcuoglu M, Başer KHC (2002). Identification of Rosemary (Rosmarinus officinalis L.) Populations in Mersin and Adana Province and Leaf Essential Oil Yields and Their Compositions. Eastern Mediterranean Forestry Research Institute Turkey 1300-7912.
Haider F, Kumar N, Banerjee S, Naqvi AA, Bagchi GD (2009). Effect of Altitude on the Essential Oil Constituents of Artemisia roxburghiana Besser var.purpurascens (Jacq.) Hook. J Essen Oil Res 21(4):303-304.

Hudaib M, Speroni E, Di Pietra AM, Cavrini V (2002). GC/MS evaluation of thyme (Thymus vulgaris $\mathrm{L}$.) oil composition and variations during the vegetative cycle. J Pharm Biomed Anal 29:691-700.

Kofidis G, Bosabilidis AM (2008). Effects of altitude and season on glandular hairs and leaf structural traits of Nepeta nuda L. Bot Stud 49:363-372.

Lodhia MH, Bhatt KR, Thaker VS (2009). Antibacterial activity of essential oils from palmarosa, evening primrose, lavender and tuberose. Indian J Pharm Sci 71(2):134-136.

Panou-Filotheou H, Bosabalidis AM, Karataglis S (2001). Effects of copper toxicity on leaves of oregano (Origanum vulgare subsp. hirtum). Ann Bot 88:207-214.

Sanon B, Azaz AD, Dirmenci T (2007). Identified Saprophytic Microfungi on the Cyclotrichium (Boiss.) Manden.\& Scheng. species distributed in Turkey. J App Bio Sci 1(3):57-59.

Smith-Palmer A, Stewart J, Fyfe L (2001). The potential application of plant essential oils as natural food preservatives in soft cheese. Food Microbiol 18:463-470.

Takaloo SG, Hassani A, Hassanpouraghdam MB, Meshkatalsadat MH, Pirzad A, Heidari M (2012). Essential Oil Content and Composition of Thymus migricus Klokov \& Desj-Shost. Affected by Plant Growth Stage and Wild Habitat Altitude. Romanian Biotechnological Letters 17(1):69826988.

Tel AZ (2009). Contributions to the flora of Nemrut Mountain (Adiyaman/Turkey). Biological Diversity and Conservation 2(1):36-60. 